\title{
Synthesis of New Oxazin Compounds Derived from Furfural, Chalcons and Schiff Bases
}

\author{
Mohammad S Al Ajely ${ }^{*}$ and A M Noori ${ }^{2}$ \\ ${ }^{* 1}$ Environmental Department, College of Environment and Technology, Iraq \\ ${ }^{2}$ Chemistry Department, Education College, Mosul University,Mosul, Iraq \\ *Corresponding author: Mohammad S Al Ajely, Environmental Department, College of Environment and Technology, Iraq
}

\begin{abstract}
Oxazine compounds have been succeeded to be used for versatile applications in various area of pharmacy, medicine and other biological uses such as Antiplatet aggregation activity, antidiabetic ,antidepressant activity ,In the investigation some new oxazine compounds have been synthesized using different routes [1]. The oxazine (A2-6) were prepared from the corresponding chalcone compounds (A1-6)by treatment of ethyl urea with these chalcones. oxazine (A5-8)were prepared from the cyclization of the corresponding compounds (A4-7) by formaldehyde compounds (A4-8)themselves were prepared by reduction of Schiff bases (A37) using NaBH4 .The third series of oxazines (A6-9)were synthesized by the reaction of furfural with hydroxyl Aromatic Compounds in methanolic ammonia. The synthesized compounds were studied by IR spectroscopy and are discussed [2].
\end{abstract}

Keywords: Oxazines; Furfural; Chalcones; Schiff bases

\section{Introduction}

Oxazine compounds were first synthesized from malonyl chloride and some aliphatic and aromatic ketones1. These oxazine compouds were also synthesized by self-condensation of malonyl chloride with nitrile componds2. Butt, Elivdge and foster found that condensation of malonyl chloride with isocyanates results into the formation of the corresponding pyrano oxazine derivatives 3. Ried, Ninninger and Bats have prepared pyrano oxazines from the condensations of malonyl chloride with thiocyanates 4 . Some of the synthesized compouds showed anticancer activities5. There are a lot of methods in the literature for the preperation of benzoxazine compouds including. ring expantion methods 6, [3] oxidation of 2-isopropyl indole with monoperphthalic acid 7 Intramolecular rearrangment8 iso cyanate precursors 9 antharanilic acid precursor $10, \mathrm{~N}$-acylantharanilc acid11, from chalcones precursors12-14 and recently pd-catalyzed carbonylation of 1-azido-2iodobenzene15.these oxazine componds have proved to have significant effect as thrombin inhibitor16 potassium modulator17, antiplatelet18,inhibitory activity toward human leukocyte elastase(HLE)19 and many other biological and medical uses 2022 .In our investigation and according to the above importance of this type of compounds we choose antharanilic acid, chalcon and Schiff bases as precursors for the synthesis of new series of oxazine compounds ,in an attempt to study their possibility to be used as drugs which is our next work [4-8].

\section{Expermintal}

All melting point were uncorrected using electro thermal melting point apparatus type SMP30 U. K, IR spectra were recorded using FTIR spectrophotometer type Bruker Alpha (ATR). All chemical were supplied by Fluke, Sigma-Aldrich companies. 2-Acetylbenzimidazole was prepared according to the published procedure22 [9-12].

\section{Synthesis of Benzimidazoyl Chalcones (A1-6)}

2- Acetyl-benzimidazole compound was prepared by chromic acid oxidation of the corresponding alcohol following the same publisher procedue23 Its structure was checked by IR and melting point in comparison with the published one .This compound was allowed to react with equimolar amount of some aromatic aldehyde following similar procedure 21 [13-18]. 


\section{General Procedure}

2- Acetyl-benzimidazole $(0.01 \mathrm{~mol}$.) was dissolved in $(30 \mathrm{ml})$ from Ethanol and $(30 \mathrm{ml})$ of water then $10 \%$ sodium hydroxide solution ( $3 \mathrm{ml}$ ) was added drop-wise to the reaction mixture, the mixture stirred for $(1 \mathrm{~h}$. ) then $(0.01 \mathrm{~mol})$ of aldehyde was added to the mixture with continuous stirring for $(3-5 \mathrm{~h})$.the solid was filtered off and recrystallized from ethanol/water [19-24].

\section{Synthesis of 4-Benzimidazoyl-6H-2-Ethylamino 1,3-0xazines(A2-6) \\ General Procedure}

Amixture of chalcone $(0.02 \mathrm{mo} .1)$, urea $(0.02 \mathrm{~mol}$.) were dissolved in ethanolic solution of sodium hydroxide $(30 \mathrm{ml})$.The reaction mixture was stirred for ( $3-4 \mathrm{~h})$ with magnetic stirre, it was then poured on $20 \mathrm{ml}$ of cold water with stirring for 1 h.then kept in refrigerator for $24 \mathrm{~h}$. the ppt was filtered off and recrystallized from ethanol $[25,26]$.

\section{Synthesis of Schiff bases(A3-6)}

\section{General Procedure}

Substituted Benzaldehyde (0.01 mol.) and substituted aniline (0.01 mol.) was dissolved in methanol $(15 \mathrm{ml})$ and two drops of acetic acid and refluxed for $(3 \mathrm{~h}$.). The resulting solution was cooled and poured in cold water. The separated solid was filtered, washed with water and crystallized from ethanol.

\section{General Procedure for the Hydrogenation of Schiff bases(A4-7)}

Each Compound of (A4-7) (0.01mol.) was dissolved in methanol (15ml.) and sodium borohydride $(0.015 \mathrm{~mol}$.) was added in small portions with stirring within 10 minutes. The reactions mixture was kept at room temperature for (1 h.). The solid separated on evaporation of most of the solvent was filtered off, washed with water and crystallized from ethanol.

\section{Synthesis of 3,4-Dihydro-3-Aryl-2H-Naph[2,1-e] [1,3] Oxazines:(A5-8)}

\section{General Procedure}

Any compound of(A3-7), (0.01mol.) and formaldehyde $(0.015 \mathrm{~mol}$.$) was dissolved in ethanol and refluxed in a water$ bath for 3 hours. The solid separated on cooling was filtered and crystallized from ethanol.

\section{Synthesis of 1,6-Bis Furyl -3,2-and4,3--Aryl-1,3- Oxazines(A6-9)}

\section{General Procedure}

Aromatic hydroxy compound $(0.01 \mathrm{~mol})$ in methanol $(10 \mathrm{ml})$ was added to Furfural and $10 \mathrm{ml}$ of $30 \%$ methanolic ammonia the final mixture was left to stand at room temperature for 3-4 days during which the crystalline product was separated out.The crude product was filtered off ,washed with cold methanol and was recrystallized from minimum amount of methanol (Figures 1-3).

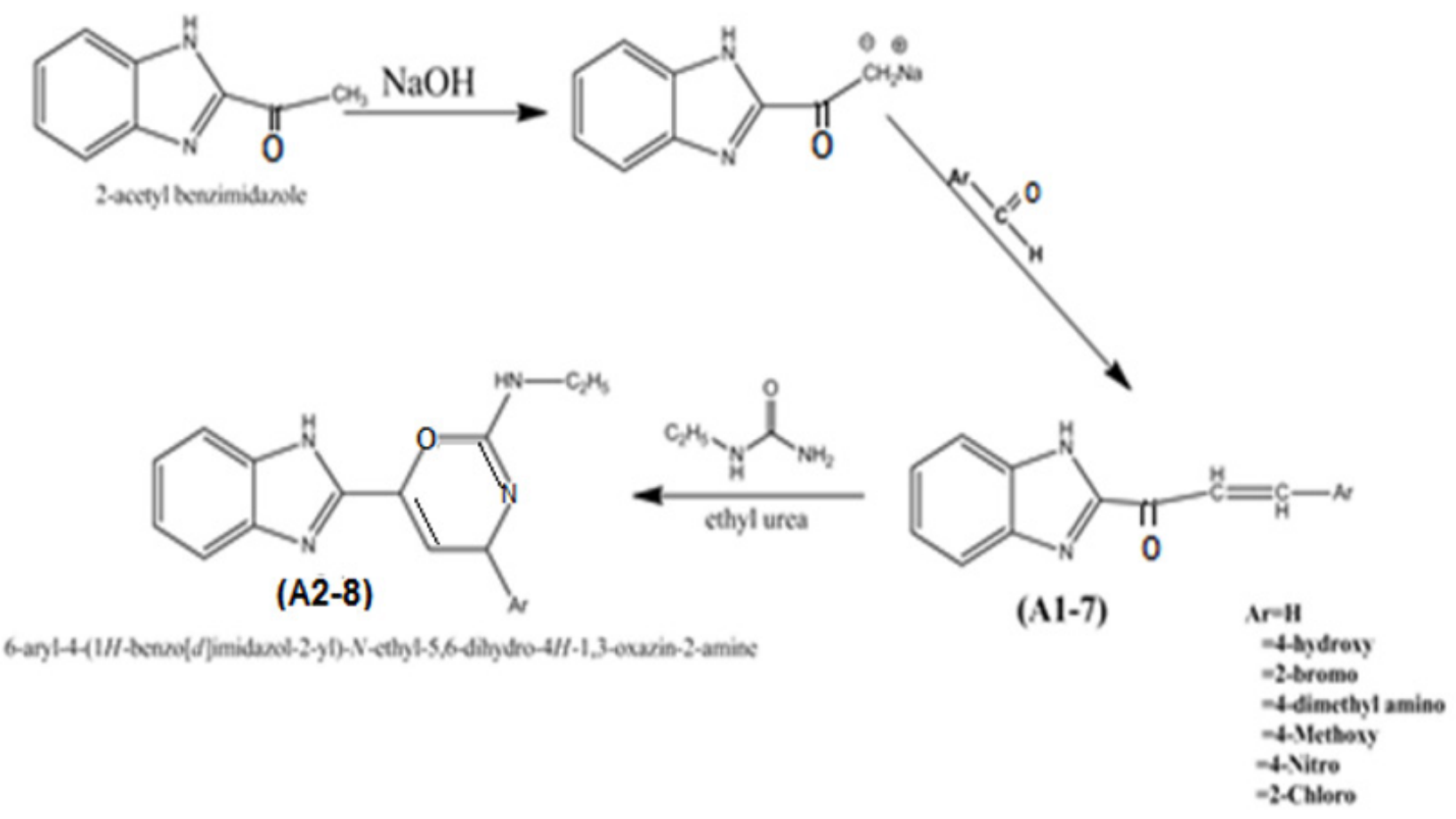

Figure 1: Sceme 1. 


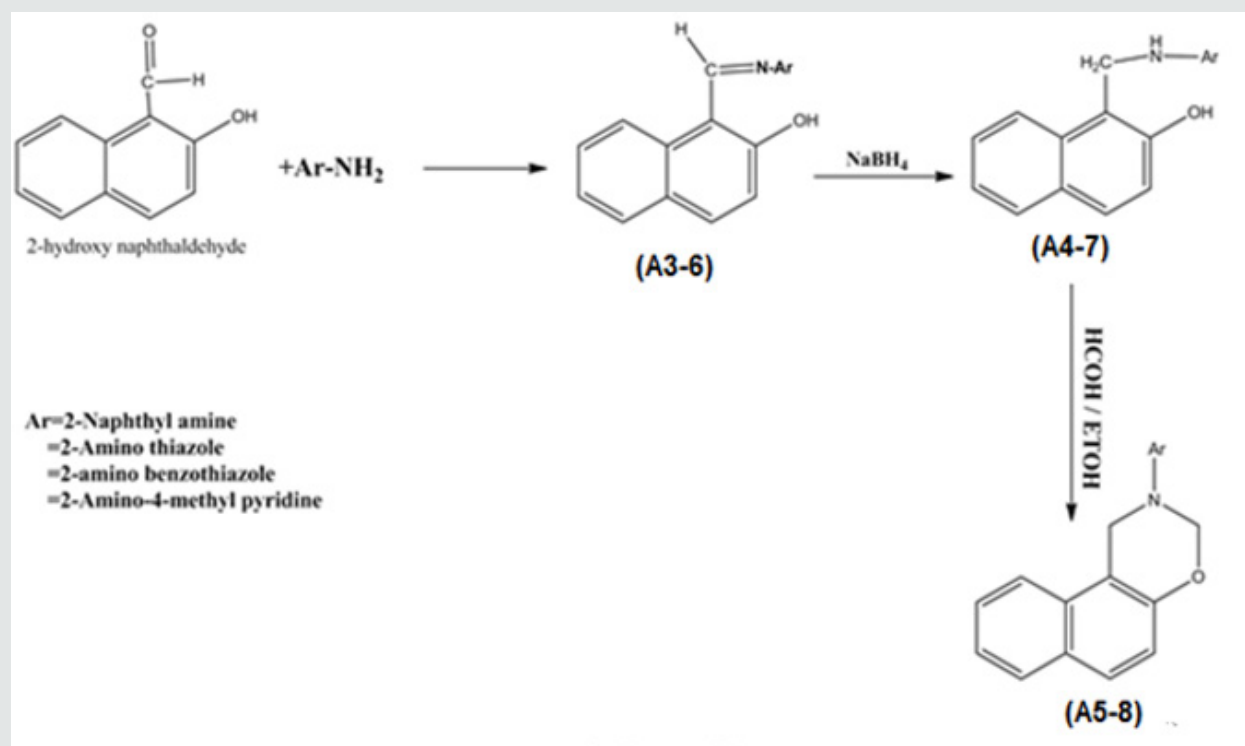

Schem (2)

Figure 2: Sceme (2).

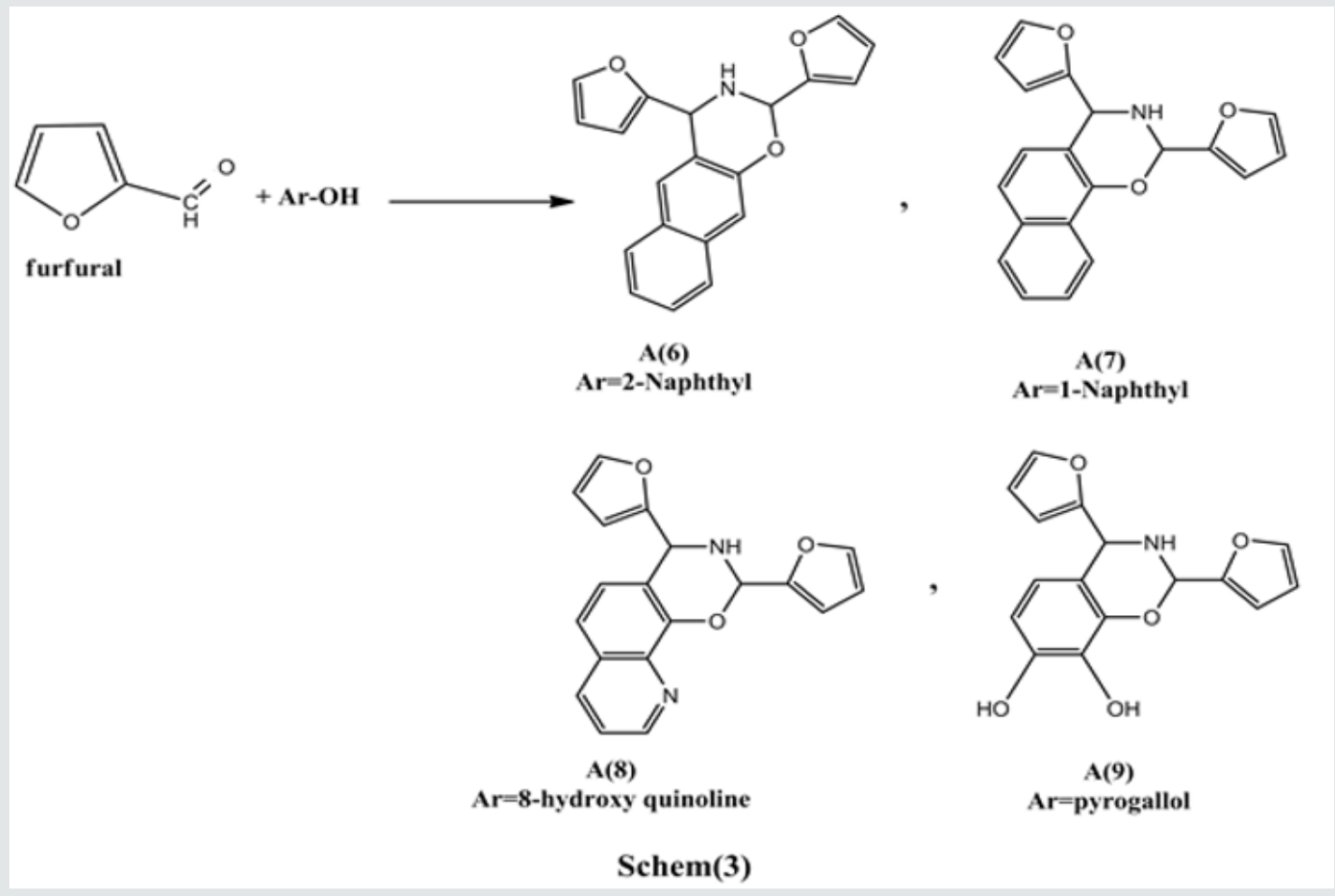

Figure 3: Sceme (3).

\section{Results and Discussion}

Chalcone compounds (A1-7) were synthesized from the corresponding 2-acetyl benzimidazole and some aromatic aldehydes as shown in scheme 1.

\section{1-(benzimidazoyl-2-yl)-3-phenyl-2-propene-1-one}

Yellowish- white, mp.142-145 ${ }^{\circ} \mathrm{C}$, yield83.58\%, IR (neet sample $\mathrm{Cm}^{-1}$ ): 1653 for $\mathrm{C}=0,1501,1507,1584$ for $\mathrm{C}=\mathrm{C} \mathrm{Ar}, 1653$ for $\mathrm{C}=\mathrm{C}, 1706$ for $-\mathrm{C}=0,3241$ for $-\mathrm{NH}$.

\section{1-(benzinidazoyl-2-yl)-3-(4-hydroxy propene-1- one}

Black Crystals, $\mathrm{mp} .265^{\circ} \mathrm{C}$, yield79.55\%, IR neet sample $\mathrm{Cm}^{-1}$ ): $1366 \mathrm{C}-\mathrm{0}, 1552$ for $\mathrm{C}=\mathrm{C} \mathrm{Ar}, 1643$ for $\mathrm{C}=\mathrm{N}, 3188$ for $\mathrm{NH}$.

\section{1-(benzimidazoyl-2-yl)-3-(2-bromophenyl)-2-propene- 1-one}

Yellow mp.216-218 ${ }^{\circ}$, yield86.3\%, IR (neet. $\mathrm{Cm}^{-1}$ ): 1326.19 for C-N,1475,1514,1587 for C=N, C=C Ar.,1655 for $-\mathrm{C}=0,3259$ for $\mathrm{NH}$. 
1-(benzimidazoyl-2-yl)-3-(4-dimethylamino)-2-propene1-one

Orange Crystals mp. $125-127^{\circ} \mathrm{C}$, yield90.33\%, IR (neet. $\mathrm{Cm}^{-1}$ ): 1341.28 for $\mathrm{C}-\mathrm{N}, 1519,1589$ for $\mathrm{C}=\mathrm{C} \mathrm{Ar}, \mathrm{C}=\mathrm{N}, 1665$ for $\mathrm{C}=0,2971.35$ for $\mathrm{CH}, 3281$ for $\mathrm{NH}$.

1-(benzimidazol-2-yl)-3-(2-methoxy phenyl)-2-propene1-one

Yellowish-Green mp.196-198 ${ }^{\circ}$, yield 54,33\%, IR (neet. $\mathrm{Cm}^{-1}$ ): 1206,1236 for C-0,1366 for C-N,1470,1513,1574 for C=C Ar., 1647 for $\mathrm{C}=\mathrm{N}, 1699$ for $-\mathrm{C}=0,1322$ for $\mathrm{NH}$.

1-(benzimidazol-2-yl)-3-(4-nitrophenyl)-2-propene-1one

Yellow Crystals mp 101-103 ${ }^{\circ} \mathrm{C}$, yield78.3 \%, IR (neet. $\mathrm{Cm}^{-1}$ ): 1333 for C-N, 1209,1512 for NO2 sym and asym., ,1590 for C=C Ar., $\mathrm{C}=\mathrm{N} 1654$ for $\mathrm{C}=\mathrm{N}, 1698$ for $\mathrm{C}=0,3113$ for $-\mathrm{NH}$.

1-(benzimidazol-2-yl)-3-(2-chlorophenyl)-2-propene-1one

Yellow Crystals $\mathrm{Mp} 212-214^{\circ} \mathrm{C}, 90.3 \%$ yield, IR (neet. $\mathrm{Cm}^{-1}$ ): 1501,1584 for $\mathrm{C}=\mathrm{C}$ Ar,1653 C=C, C=N,1766 for $-\mathrm{C}=0,3241$ for $-\mathrm{NH}$.

\section{Oxazines from Chalcones}

The above compounds were synthesized from the corresponding chalcones with ethyl urea as stated above the IR data were in agreement with similar published one12,13

\section{6-(Benzimidazol-2yl)-2-Ethylamino-4-Phenyl-4H-1,3-} Oxazine-4H-1,3-0xazine

White solid crystals mp.193-196 ${ }^{\circ} \mathrm{C}$ published:193-194 oC yield 90\%.IR (neet.cm ${ }^{-1}$ ): 1501,1507,1587 Ar C=C, 1653 C=N, 3240.75 $\mathrm{N}-\mathrm{H}$.

\section{6-(benzimidazol-2yl)-2-ethylamino-4-(4-hydroxy phenyl} -4H-1,3-0xazine

Brownish Crystals, $\mathrm{mp} 36-38^{\circ} \mathrm{C}$, yield $85 \%$ IR (neet. $\mathrm{cm}^{-1}$ ).

6-(benzimidazol-2-yl)-2-ethylamino-4(2-bromo phenyl)4H-1,3-0xazine)

Yellow crystals, mp. $206-209^{\circ} \mathrm{C}$, yield $91 \%$, IR (neet. $\mathrm{Cm}^{-1}$ ): 1270,1206 for C-0, 1326.19 for C-N,1513,1587 for C=C Ar., 1654 for $\mathrm{C}=\mathrm{N}, 3264$ for $\mathrm{NH}$.

6-(benzimidazol-2-yl)-2-ethylamino-4-(4-dimethylamino phenyl)-4H-1,3-0xazine

Orange crystals, mp. $178-180^{\circ} \mathrm{C}$, yield $90 \%$, IR (neet. $\mathrm{Cm}^{-1}$ ): 1216,1333 for C-O, 1512,1576 Ar C=C,1341 for C-N,1638 for $\mathrm{C}=\mathrm{N}, 3257$ for $\mathrm{NH}$.

6-(benzimidazol-2-yl)-2-ethylamino-4-(2-methoxy phenyl)-4H-1,3-0xazine

Yellowish-white crystals, mp $188-191^{\circ} \mathrm{C}$, yield $87 \%$, IR (neet. $\mathrm{Cm}^{-1}$ ): $1236.22,1322.36$ for $\mathrm{C}-\mathrm{O}$ sym and asym.,1322.36 for C-N, 1513.27,1574 for $\mathrm{C}=\mathrm{C}$ Ar., 1647 for $\mathrm{C}=\mathrm{N}, 3247.72$ for $\mathrm{NH}$.
6-(benzimidazol-2-yl)-2-ethylamino-4-(4-nitrophenyl)4H1,3-0xazine

Brown crystals, mp. $205-207^{\circ} \mathrm{C}$, yield $92 \%$, IR (neet. $\mathrm{Cm}^{-1}$ ): 1215,1333 for C-0,1216 for sym.NO2,1512.5 for asym.1333 for C-N,15190,1576 for C=C Ar., 1652 for $\mathrm{C}=\mathrm{N}, 3257$ for $\mathrm{NH}$.

6-(benzimidazol-2-yl)-2-ethylamino-4-(2-chlorophenyl)4H1,3-0xazine

Yellowish-white crystals, mp $201-203^{\circ} \mathrm{C}$, yield $87 \%$, IR (neet. $\mathrm{Cm}^{-1}$ ): 1273,1325 for C-O, 1325.90 for $\mathrm{C}-\mathrm{N}, 1476,1504,1585$ for $\mathrm{C}=\mathrm{C}$ Ar. 1652 for $\mathrm{C}=\mathrm{N}, 3257$ for $\mathrm{NH}$.

\section{Schiff Bases(A3-6)}

The above Schiff bases were synthesized by treatment of 2-hydroxy naphthaldehyde with some amines see scheme 2 . These compounds were characterized by the Main IR bands as below;

\section{2-Hydroxy Naphylidine-1- Naphthyl Amine}

Deep brown crystals, mp. $182-185^{\circ} \mathrm{C}$, IR (neet. $\mathrm{Cm}^{-1}$ ):1605 For $\mathrm{C}=\mathrm{C}$ Ar . and $\mathrm{C}=\mathrm{N}, 1330$ for $\mathrm{C}-\mathrm{O}, 3440$ for $-\mathrm{OH}$.

\section{2-hydroxy naphylidine-2-thiozolyl amine}

Yellow Crystals, mp. $158-160^{\circ} \mathrm{C}$, yield $88 \%$ IR (neet. $\mathrm{Cm}^{-1}$ ): 740.37 for C-S,1458.98,1468.96 for C=C Ar.,1128,1219 for C-0,1604for $\mathrm{C}=\mathrm{N}, 3009,3273.59$ for $\mathrm{C}-\mathrm{H}, 3558$ for $-\mathrm{OH}$.

\section{2-hydroxy naphylidine-2-benzothiazol-2-yl amine}

Oarrange crystals mp. $196-199^{\circ} \mathrm{C}$, yield68.9\%, IR (neet. $\mathrm{Cm}^{-}$ $\left.{ }^{1}\right): 737.08$ for C-S,1139,1306 for C-0, 1139,1306.3 for C-0,1548.68, 1463.89 for $\mathrm{C}=\mathrm{CAr} .1596$ for $\mathrm{C}=\mathrm{N}, 3410$ for $-\mathrm{OH}$.

2-hydroxy naphylidine-2(4-methyl pyridine-2-yl) amine

Yellowcrystals, mp. $177-179^{\circ} \mathrm{C}$, yield $69 \%$, IR (neet. $\mathrm{Cm}^{-}$ 1):1126,1276 for $\mathrm{C}-0,1599,1528,1480.5$ for $\mathrm{C}=\mathrm{C} \mathrm{Ar}, \mathrm{C}=\mathrm{N}, 3026$ for $\mathrm{C}-\mathrm{H}, 3363$ for- $\mathrm{OH}$.

\section{Schiff Bases Reduction, The Synthesis of Arylamino Naphthos(A4-7)}

Schiff bases reduction was accomplished byNaBH4 at room temperature as stated in the experimental part see scheme 2 . The reaction with this reagent cause to color change of the colored Schiff bases into white or faint colored products.

\section{1-Naphthyl amino methyl 2- naphthol}

Brownish yellow crystals, mp.86-92 ${ }^{\circ} \mathrm{C}$, yield $83.4 \%$, IR (neet. $\mathrm{Cm}^{-1}$ ):759.99for NH def.,1257,1357 C-0,1466,1516,1580 C=C Ar.,3042.7 CHstr.,3326.7 NH, 3542 for $\mathrm{OH}$.

\section{2-Thiazol-2-yl amino methyl-2-naphthol}

White crystals, mp. $193-196^{\circ} \mathrm{C}$, yield $89.3 \%$, IR (neet. $\mathrm{Cm}^{-}$ $\left.{ }^{1}\right)$ : $744.3,812.36$ for $\mathrm{NH}$ def.,1215,1270,1339.94 C-0,1443, 1540,1597.8 for C=C Ar. ,3009CH,3272NH,3488 for OH.

\section{2-Benzothiazol-2-yl Amino methyl -2- naphthol}

Faintorange -white crystals, mp.171- $173^{\circ} \mathrm{C}$, yield92.3\%, IR (neet $\mathrm{Cm}^{-1}$ ):737.39,898.33 N.H def. 
for $\mathrm{OH}$.

\section{(2-Amino -4-methyl pyridyl) methyl -2- naphthol}

White crystals, mp. $154-157^{\circ} \mathrm{C}$, yield $90.98 \%$, IR (neet. $\mathrm{Cm}^{-}$ 1):731.07,793,851 for NH def.,1223,1333.27 C-0,1464.41,1507.8 $\mathrm{C}=\mathrm{C}$ Ar.,3045for $\mathrm{CH}, 3355.1$ for $\mathrm{OH}$.

\section{Aryl Oxazine from Reduced Schiff Bases(A5-8)}

\section{3-(1-Naphthyl)-3H-2,4-Dihydro[2,1-e] [1,3] Naphthaoxazine}

Red-Orange crystals, m.p159- $162^{\circ} \mathrm{C}$, yield $64.1 \%$, IR (neet. $\mathrm{Cm}$ $\left.{ }^{1}\right): 1152$ for C-N, 1024,1226, C-O-C,1462,1510,1584 for C=C Ar,3060 $\mathrm{C}-\mathrm{H}$

\section{3-(2-aminothiazol-2-yl)-3H -2,4-dihydro[2,1-e] [1,3] naphthaoxazine}

Brownish yellow crystals, mp. $191-193^{\circ} \mathrm{C}$ yield $79.87 \%$, IR (neet. $\mathrm{Cm}^{-1}$ ): 808 for C-S1067for C-N,1067,1225.59 for C-O-C,1445,1519.79,1588.72 for C=C Ar,3060 for C-H.

\section{3-(2-aminobenzothiazol-2-yl)-3H-2,4-dihydro[2,1-e] $[1,3]$ naphthaoxazine}

Brown crystals, m.p $103-106^{\circ} \mathrm{C}$ yield95.6\%,IR (nee.t $\mathrm{Cm}^{-1}$ ):729.4 for C-S,1122.46forC-N ,1156.3,1213 for C -0C,1445,1538,1586.6,1607 for C=C Ar.,2998,3133 for C-H.

\section{3-(2-amino-4-methyl pyridine-2-yl)-3h-2,4-dihydro[2,1-e] $[1,3]$ naphthaoxazine}

White crystals, $\mathrm{mp} .98-101^{\circ} \mathrm{C}$, yield $80.73 \%$, IR (neet. $\mathrm{Cm}^{-1}$ ): 935.9for C-N,1163,1224.9 for C-O-C,1431,1557.13for C=C Ar,1602 for $\mathrm{C}=\mathrm{N}, 2902,3002$ for $\mathrm{C}-\mathrm{H}$.

\section{2,4 Bis furyl naphthyl oxazines(A6-9)}

These compounds were synthesized by treatment of furfural with some hydroxyl aromatic aldehydes as shown in scheme 3

\section{2,4-Bis furyl-2-,4-dihydro-2H[3,2-e] [1,3] naphtha oxazine(A6)}

Rrown crystals, mp. $103-105^{\circ} \mathrm{C}$, yield $86.35 \%$, IR (neet. $\mathrm{Cm}^{-1}$ ):1083,1265.43for sym. andasym.C-0,1323.12 forCN,1588.43,1609C=c Ar.,3066 for C-H and 3311.87 for- NH.

\section{2,4-Bisfuryl-2,4-dihydro-2H-[4,3-e][1,3]naphthaoxazine(A7)}

Bronish-yellow crystals, Mp. $97-100^{\circ} \mathrm{C}$, yield $82.8 \%$, IR (neet $\mathrm{Cm}^{-1}$ ): 1072.32,1223.47 for C-O-C,1381.92 for C-N,1569.36,1461.18 for $\mathrm{C}=\mathrm{Car}, 3062.83 \mathrm{C}-\mathrm{H}, 3362.7$ for $-\mathrm{NH}$.

\section{2,4-Bis furyl-2-,4-dihydro-2H-[7,6-e] [1,3] qunoloxazine(A8)}

Brown crystals, mp., $125-127^{\circ} \mathrm{C}$, yield $92 \%$, IR (neet. $\mathrm{Cm}$ 1):1081,1225.31for C- O-C,1505C=Car.,1368 C-N,1636.47 for $\mathrm{C}=\mathrm{N}, 3065 \mathrm{C}-\mathrm{H}$ and3275.34 for $-\mathrm{NH}$.

\section{2,4-Bis furyl-2-,4-dihydro-3H-[10,9-e] -7,8-dihydroxy [1,3] benzoxazine(A9)}

Brown crystals, $\mathrm{mp} .330^{\circ} \mathrm{C}$, yield $92 \%$ IR (neet. $\mathrm{Cm}^{-1}$ ): 1461,081,1229.26 for C-O-C,1381.92 C-N,1461.16,1569.36 for C=C Ar.,3273 for C-H,3362.7 for- NH.

\section{Conclusion}

It is clear from the above results that all furfural, Schiff base and chalcone precursors formed 1,3- oxazine compound this finding is in agreement with similar published compounds24-26 for chalcones and as it was mentioned in the introduction for Schiff bases and furfural precursors.

\section{Acknowledgement}

Authors would like to thank Iraqi ministry of Higher Education and research for offering Ahmed scholarship, Thanks also to the chemistry department of Mosul university for providing the facility as possible as they can to do this work which is part of Ahmed MSc. Thesis.

\section{References}

1. Davis SJ, Elvidge JA (1952) Heterocyclic synthesis with malonyl chloride part 1pyrano-1,3-dioxan fromketones. J chem soc, Pp. 4109.

2. Davis SJ, Elvidge JA (1953) Heterocyclic synthesis with malonyl chloride part II 2,2-disubstituted-6-amino-2,4-diketo pyrano (3:4:5:6) 1,3 Di oxans and simple derivatives of 4-keto1,3-dioxan. J Chem Soc, pp. 2251.

3. Davis SJ, Elvidge JA (1962) Heterotcyclic synthesis with malonyl chloride parpyrano- dioxafroman enolicketone, diketones and benzaldehyde, modification of thedoebner condensation. Journal of Chem Soc, pp. 3350.

4. Elvidge JA (1962) Heterocyclic synthesis with malonyl chloride partIII the course of reaction with simple ketones and additional evidence for the condensation of the products. J Chem Soc, pp. 2606.

5. Al Ajely MS, Al Abachi FT (2000) New method of preparation of the comp. (6-chloro-2-methyl thio-2-N- ethyl carbazato-2,3 di hydropyrano[3,4-e] $[1,3]$-oxazine-4,5-dione and the study of its use as antitumor agent Iraqi Patent No. 2807.

6. Davis M, Pogany SP (1977) Boylation of 5-substituted-1H-benzo[c] isothiazole-3-one. Journal of Heterocyclic chem 14: 267.

7. Askawa H, Imamiya Y, Kawamatsu Y (1979) Synthesis of benzoxazines from2-hydroxy indole derivatives. Chem Pharm Bull 27: 522.

8. Balsubramaniyan V, Argade NP (1986) synthesis of6-chloro-2-methyl4h-3,1 benzoxazin-4-one derivatives via intramolecular rearrangement of 7-chloro-1,4-benzodiazepin-2,5-one. Tetrahedron let 27:2487.

9. Deck LM, Tamer SD, Deck TA (2001) Synthesis of substituted benzoxazines via the cyclization of $\mathrm{N}$ - substituted antharanilate. Journal Heterocyclic Chem 38: 343.

10. Colson E, Wallach J, Hauteville M (2005) Synthesis and antielastase properties of6-amino-2-phenyl-4H-3,1-benzoxazin-4oneaminoacylanddipeptideyl derivatives. Biochimie 87: 223-230.

11. Khabazzadeh H, Saidi K, Sheibani H, Tavakolinejad E (2008) Solvent free synthesis of benzoxazin-4-ones from $\mathrm{N}$-acetyl antharanilic acid derivatives. Iranian Journal of organic chemistry 1: 43-45.

12. Thirunarayanan G, Sundararajan R, Arulkumaran R (2014) Aryl Chalcones as Efficient Precursors for Deriving Oxazine: Solventfree Synthesis and ti microbial Activities of some 0xazine-2-amines. International Letters of Chemistry, Physics and Astronomy 23: 82-97.

13. Amer Sallal Z (2014) Synthesis and characterization of new Oxazine, Thiazine and Pyrazol derived from chalcones. Baghdad Science Journal 11(2): 477-485.

14. Chaitra RM G, Rohini (2018) Synthesis of 1,3-Oxazine derivative from Chalcone and Screening for their Anti-0xidant and Anti-Inflammatory activity. International Research Journal of Pharmaceutical and Biosciences 4 (6): 19-27. 
15. In Youcan Y, Wang H, Wu K (2019).

16. Wu CC, Wang TW, Wang WY, Hsieh PW, Wu YC ( 2-(2005)2-Bromo phenyl)-8-methoxy-benzoxazinone (HPW-RX2), a direct thrombin inhibitor with a suppressive effect on thromboxane formation in platelets. Eur J Pharmacol.19 527 (1-3): 37-43.

17. Caliendo G, Rieco GP, Perissutti E, Santagada V, Santini A, et al. (1998) Synthesis, biological activity and conformational study of 1,4-benzoxazinederivatives as potassium channel modulators. Eur j med c 33(12): 957-967.

18. Pritchard KM, Rawi JA, Bradley C (2007) Synthesis, identification and antiplatelet evaluation of 2-morpholino substituted benzoxazines. Eur J Med Chem 42(9): 1200-1210.

19. Lulu Wang, Haribabu Ankati, Shashidhar Kumar Akubathini, Michael Balderamos, Chelsey A. Storey, et al. (2010) Identification of novel 1,4benzoxazine compounds that are protective in tissue culture and in vivo models of neurodegeneration. J of Nuro Science Research 88 (9): 19701984.

20. Dong Z, Cheng Y, JZhao , Su L, BZhao (2010) Discovery of a benzoxazine derivative promoting angiogenesis in vitro and in vivo. J Cell Physiol 223(1): 202-208
21. Abd Elsalam Sharaf Eldin N (2019) 3,4-dihydro-2H-1,3-benzoxazines and their oxo-derivatives chemistry and bioactivity. J Serb Chem Soc 83(0): 1-36.

22. Kishore Kumar P, Dubey PK (2012) Studies on preparation of 2-Acetylbenzimidazole. Der Pharma Chemica 4(3): 1292-1295.

23. Thirunarayanan G, Sundararajan R, Arulkumaran R (2014) Aryl Chalcones as Efficient Precursors for Deriving0xazine: Solvent-free Synthesis and Antimicrobial Activities of some Oxazine-2-amines. International Letters of Chemistry, Physics and Astronomy 23: 82-97.

24. Jsonia Dsonia T, Arikkat T, Vincent G, Chandran M, Ar bhat, et al. (2013) biological activities of oxazine and its derivatives: a review. international journal of pharma sciences and research (ijpsr) 4(11): 134-143.

25. Tony G, Chandran M, Bhat AR, Krishnakumar K (2014) Molecular docking studies: 1, 3-thiazine and 1,3-oxazine dervatives. Journal of Pharmacy Research 8(2): 136-138.

26. George M, Joseph L, Sadanandan Raj (2016) A Research on Synthesis of Oxazine Derivatives \& Screening of Oxazine Derivatives for Certain Pharmacological Activities. International J of pharmacy and pharmaceutical research 6(3): 14-42.

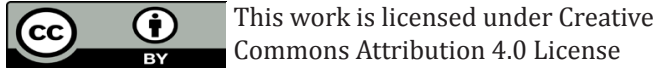

To Submit Your Article Click Here:

Submit Article

DOI: $10.32474 /$ LOJPCR.2019.01.000113

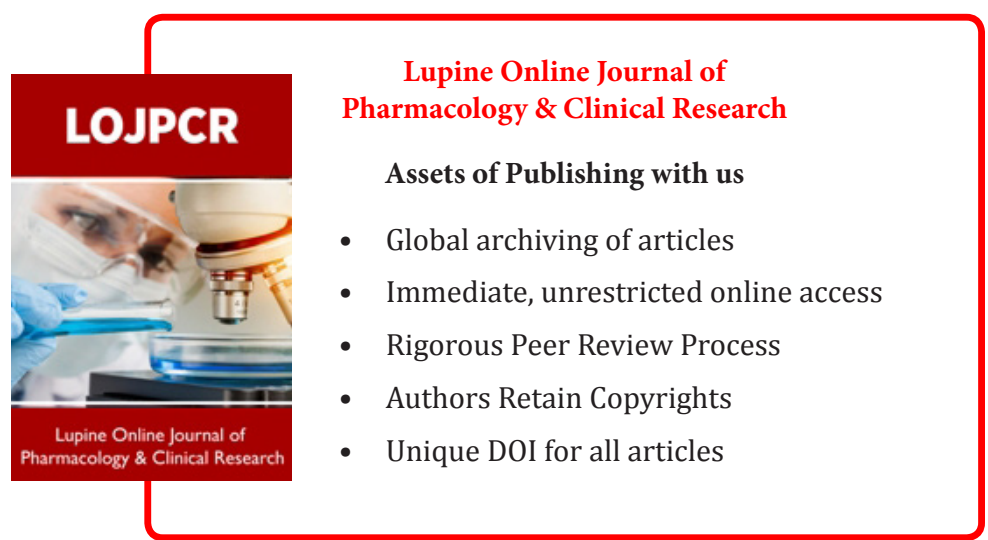

